\title{
The effect of zinc supplementation on cigarette smoke-induced nephrotoxicity in rats
}

\author{
Arif Duran $^{\text {a* }}$, Zeynep Ocak ${ }^{\mathrm{b}}$, Tarık Ocak ${ }^{\mathrm{a}}$, Hakan Elcin Terzic ${ }^{\mathrm{c}}$, Alim Erdem $^{\mathrm{d}}$, Ertuğrul Mevlüt Kocaman $^{\mathrm{b}}$ \\ ${ }^{a}$ Department of Emergency Medicine, Faculty of Medicine, Abant Izzet Baysal University, Bolu, Turkey \\ ${ }^{b}$ Department of Medical Genetics, Faculty of Medicine, Abant Izzet Baysal University, Bolu, Turkey \\ ${ }^{c}$ Department of Histology and Embryology, Faculty of Medicine, Abant Izzet Baysal University, Bolu, Turkey \\ ${ }^{d}$ Department of Cardiology, Faculty of Medicine, Abant Izzet Baysal University, Bolu, Turkey
}

\section{ARTICLE INFO}

\section{Article History}

Received $\quad 02 / 06 / 2013$

Accepted $\quad 15 / 08 / 2013$

\section{* Correspondence to:}

Arif Duran

Department of Emergency Medicine,

Faculty of Medicine,

Abant Izzet Baysal University,

Bolu, Turkey

e-mail:drarifduran@gmail.com

\section{Keywords:}

Interleukin

Nuclear factor of kappa light polypeptide

Gene enhancer in B-cells

Renal injury

Smoke

Toll-like receptor

Zinc

\section{ABSTRACT}

The aim of our study was to investigate the effect of zinc-supplemented diet on the cigarette smoke-induced changes on toll-like receptor (TLR), nuclear factor of kappa light polypeptide gene enhancer in B-cells (NFKB) and cytokine gene expression in renal tissue of rats. A total of 24 Wistar albino rats were allocated into four groups as group A: Non-smoke controls (n:6), group B: Non-smoke+zinc (n:6), group C: Smoke (n:6), and group D; smoke+zinc (n:6). RNA isolation was performed from the renal tissues of the rats which were sacrificed at the end of the $12^{\text {th }}$ week. The expression levels of TLR2, TLR4, NFKB1, NFKB2 and interleukin 1 alpha (IL1A), interleukin 10 (IL10) genes were evaluated using the Reverse Transcription Polymerase Chain Reaction (RT-PCR). In addition, these tissues were examined histopathologically and the direct protective effect of zinc on these tissues was investigated. No significant difference was found between the groups in terms of TLR2 and TLR4, NFKB1 and NFKB2, IL1 and IL10 gene expression levels. As a result of the histopathological assessment, a statistically significant difference was detected between Group A, C and D in terms of hemorrhage, congestion, inflammation, glomerular atrophy and tubular injury $(\mathrm{p}<0.05)$. The zinc supplementation may have a protective effect from cigarette smoke-induced nephrotoxicity in rats.

\section{J. Exp. Clin. Med., 2013; 30:353-356}

\section{Introduction}

Smoking is known to affect many tissues and systems, mainly the cardiovascular system and the respiratory system (Khanna et al., 2009). Smoke has also recently been reported to have negative effects on renal functions (Özbek, 2012). Epidemiological studies have revealed that smoking is a risk factor for development of nephropathy through different mechanisms. Free oxygen radicals (FOR)-induced nephrotoxicity is one of these mechanisms. Zinc $(\mathrm{Zn})$ is one of the most important antioxidant agents in the fight against FOR-induced injury (Orth, 2002; Pedregosa et al., 2011; Ryua et al., 2011). The positive effects of zinc have been shown in many experimental models in which oxidative stress plays a role, such as ischemia, ulcer and drug toxicity (Murra et al., 2012). The unknown effect of smoke on the renal tissue and methods to prevent effects of the harmful are a novel research area.

The aim of our study was to investigate the effect of zincsupplemented diet on the cigarette smoke-induced changes in toll-like receptor (TLR), nuclear factor-kappa B (NFKB) and interleukin (IL) gene expression in renal tissue of rats. 


\section{Material and methods}

The study protocol was approved by the Local Ethical Committee of Laboratory Animals at Abant Izzet Baysal University.

\section{Animals and treatment}

A total of 24 female Wistar albino rats weighing between $250 \mathrm{~g}$ and $300 \mathrm{~g}$ were used in our study. The environmental conditions were set as dark-light intervals for 12 hours. The rats were randomized into four groups as follows: Group A: Non-smoke controls (n: 6), group B: Non-smoke+zinc (n: 6), group C: Smoke (n: 6), group D: Smoke+zinc (n: 6).

The protocol prepared by Chen et al.(2010) was used to expose the rats to cigarette smoke. A 50x35x36 cm cabin with a thickness of $0.5 \mathrm{~mm}$ and internal volume of $0.060 \mathrm{~mm}^{3}$ was prepared and isolated with silicone. A plastic tube joined to an aquarium motor was placed with one end outside. The rats which would inhale smoke were placed in the cabin. Two smoking cigarettes were joined to the end of the tube in the cabin and puffed with a motor. The duration of smoking of a cigarette was recorded as a mean of seven minutes. Five minutes of normal respiration time was given between two cigarettes. The feeding procedures of the rats were divided as normal and high zinc content. While the amount of zinc was $22 \mathrm{mg} / \mathrm{kg}$ in the normal diet, it was $150 \mathrm{mg} / \mathrm{kg}$ in the high zinc content group. Anesthesia was administered to all the rats through an intramuscular injection of $50 \mathrm{mg} / \mathrm{kg}$ ketamine hydrochloride and $8 \mathrm{mg} / \mathrm{kg}^{-1}$ xylazine at the end of the $12^{\text {th }}$ week. All the rats were sacrificed thereafter. Renal tissue was carefully decapsulated. Half of the obtained tissues were carried into liquid nitrogen and stored at $-80^{\circ} \mathrm{C}$ until being used. The other half of the renal tissue samples were placed in $10 \%$ formaldehyde solution.

\section{Molecular genetics evaluation}

Expressions of cytokine (IL1, IL10, NFKB1, NFKB2) and toll-like receptors (TLR2, TLR4) were analyzed using the real time reverse transcription- PCR (RT-PCR) on the 7500 Fast RT-PCR System following the suggested manufacturer's cycling parameters (Applied Biosystems, Foster City, CA). Tissue homogenization was performed on "MagNa Lyser" using the "MagNA Lyser Green Beads". Total RNA was extracted from the renal cells using the RNA Mini Kit (Ambion@ PureLink). RNA was then quantified and quality-tested by UV spectrophotometry. The volumes of the RNA samples were equalized and RNA was then converted to cDNA by using the High capacity RNA to cDNA kit. Primers and probes were determined according to Applied Biosystems, TaqMan Assays on Demand. Gene expressions were carried out by applying TaqMan ${ }^{\circledR}$ Gene Expression Master Mix according to the TaqMan ${ }^{\circledR}$ Gene Expression Assays protocol. At the Real Time stage, using 6,25 ng/ $\mu \mathrm{l}$ of cDNA/gene, 7 genes were investigated in each sample. The amplification of a housekeeping gene, $\beta$-Actin, was used for normalizing the efficiency of cDNA synthesis and the amount of RNA applied. This process was repeated for each sample on three consecutive days. Relative quantification of mRNA was carried out using the comparative CT $(\Delta \Delta \mathrm{Ct})$ method. The calculation was obtained according to the formula written below (Livak et al., 2001): $\Delta \Delta \mathrm{Ct}=(\mathrm{Cttarget}$ gene $-\mathrm{Ct}$ reference gene). This result was applied to $2^{-\mathrm{AACt}}$ to calculate the rate of gene expressions to demonstrate the number of times in which there was an increase or a decrease depending on the control group.

\section{Histopathological evaluation}

All kidney samples were sectioned and fixed on $10 \%$ formalin, and then dehydrated and embedded in paraffin. The tissues were then sectioned at $3 \mathrm{um}$ and stained with hematoxylin and eosin (H\&E), followed by semi-quantitative analysis of the kidney sections by a single pathologist using the blind protocol. Histopathological changes were evaluated for all parameters as 0 : no histopathological changes; 1 : Less than 10\% histopathological changes; $2: 10-30 \%$ histopathological changes; 3: More than 30\% histopathological changes. The obtained data were recorded on a form. The inter-group assessments were evaluated statistically using the SPSS program.

\section{Statistical Analysis}

The $\Delta \Delta \mathrm{Ct}$ analysis of the samples was performed using RTPCR. In the statistical analysis of the obtained data, $\Delta \Delta C T$ values indicating the expression amounts of TLR2, TLR4, NFKB1, NFKB2, IL1, IL10 genes were re-calculated as $2^{-\Delta \Delta C T}$. The Kruskal Wallis test was used in order to determine whether the expression levels of the genes differed between the groups or not. All groups were compared by non-parametric Mann-Whitney U and Chi-Square tests for histopathological changes. The SPSS 17.0 package program was used for all the statistical analyses and a p level of $<0.05$ was accepted as statistically significant.

\section{Results}

\section{Evaluation of the IL1, IL10, NFKB1, NFKB2, TLR2 and} TLR4 genes

Multiple analyses were performed between smoke or nonsmoke: Zinc-rich diet- and normal diet-administered rat groups. The gene expression levels in all groups is presented comparatively in Figure 1. When the gene expression values of all the groups were compared no significant difference was observed between TLR2 and TLR4, IL1 and IL10, NFKB1and NFKB2 gene expression levels. Despite the P value being higher than 0.05 it is much closer to the reference $P$ value $(\mathrm{p}<0.05)$

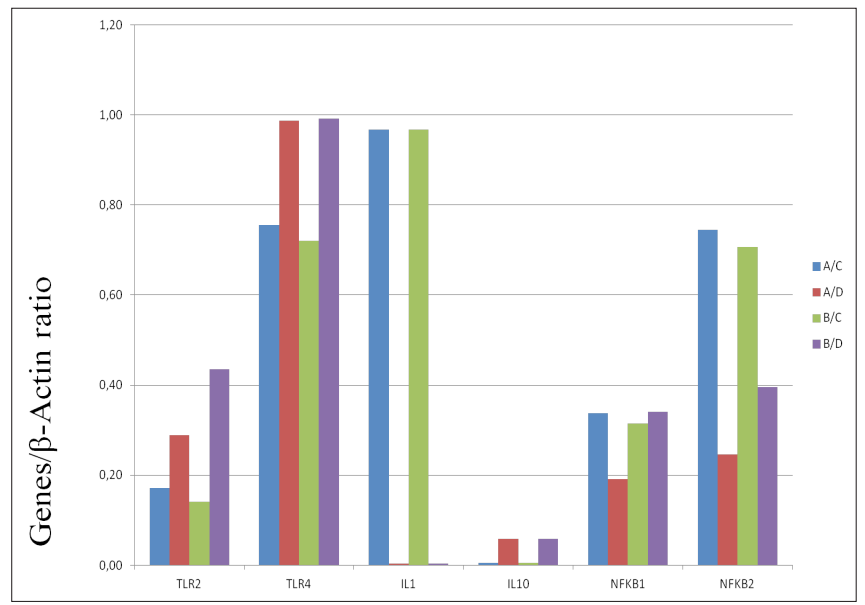

Fig. 1. The gene expression levels in all groups. 


\section{Histopathological results}

In the statistical analysis between Group $\mathrm{A}$ and $\mathrm{B}$, no significant difference was detected in terms of hemorrhage, congestion, inflammation, glomerular atrophy and tubular injury ( $p>0.05$ ). In the statistical analysis between Group A, $\mathrm{C}$ and $\mathrm{D}$ a statistically significant difference was detected in terms of hemorrhage, congestion, inflammation, glomerular atrophy and tubular injury $(\mathrm{p}<0.05)$ (Fig. 2A, B). In the statistical analysis between Group B and C, a statistically significant difference was detected in terms of hemorrhage, congestion, glomerular atrophy $(\mathrm{p}<0.05)$ (Fig. 3A, B, C). In the statistical analysis between Group B and D, a statistically significant difference was determined in terms of congestion, inflammation, and glomerular atrophy $(\mathrm{p}<0.05)$. In the statistical analysis between Group C and D, no statistically significant difference was determined in terms of hemorrhage, congestion, inflammation, glomerular atrophy and tubular injury ( $>00.05)$ ( Fig. 4A, B).

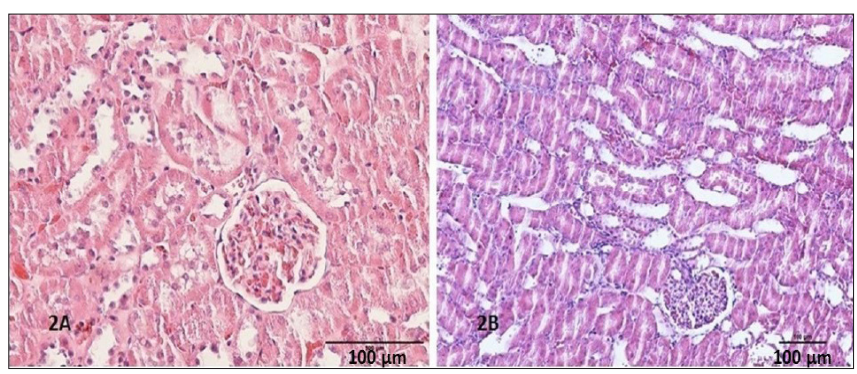

Fig. 2. Renal tissues of the rats fed with normal diet (A) and zincrich diet (B) are seen to be normal.

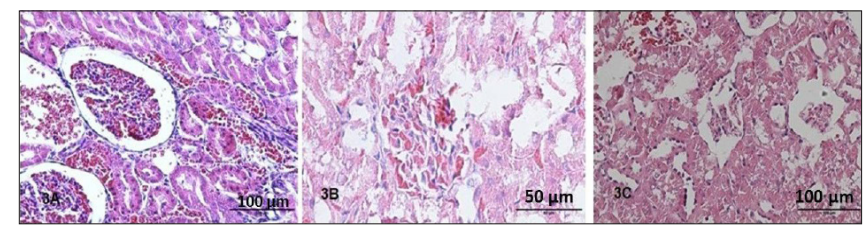

Fig. 3. A; Vascular dilation and congestion are seen in the renal tissues of rats and the Bowman's space is seen to have enlarged in some areas. B-C; Bowman's space is seen to become blurred and tubular structures around this glomerule are seen to be destroyed, epithelium is seen to spill and has an atrophic appearance. Some glomerular structures are seen to have diminished in size and become contracted.

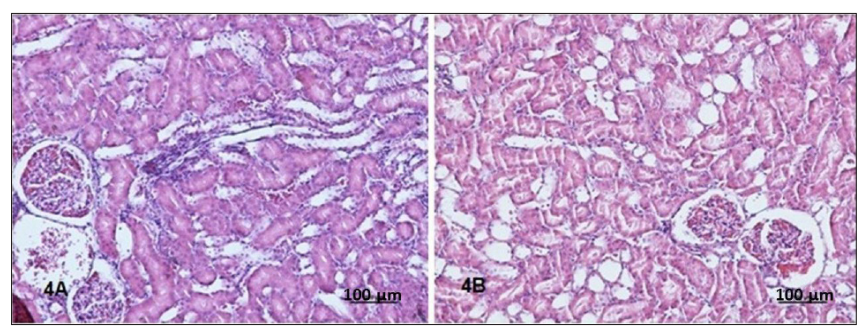

Fig. 4A-B. Congestion and dilation are seen to decrease in renal tissues of the rats which smoked and which were fed with zinc-rich diet, and inflammatory cells are seen around some glomerular structures. When compared with the smoke group, degenerated tubule structures were seen to be of lower numbers. Enlargement of the Bowman's space continued although to a lower extent. Some tubular structures around those structures were seen to have enlarged.

\section{Discussion}

This study shows that, when compared with each other, no significant difference was observed between TLR2 and TLR4, IL1 and IL10, NFKB1 and NFKB2 gene expression levels in any of the groups. However, the expression levels demonstrated in all groups and the low sample numbers affected statistical analyses. The most important limitation of our study is that due to the insufficient number of samples, we did not find any statistical significance despite all the observed differences.

TLRs may contribute to renal diseases through various mechanisms. Over-activation of these receptors has been shown to be associated with ischemic renal diseases, acute renal injury, end-stage renal failure and acute tubulointerstitial nephritis (Gluba et al., 2010). However, its role in smokeinduced nephrotoxicity is not clear. Although not statistically significant, our results demonstrate that cigarette smoke causes a decrease in the renal expression of TLR2, and zinc increases the renal TLR2 expression levels in rats exposed to cigarette smoke when compared to the control group. Rats that were exposed to both zinc and cigarette smoke had similar renal TLR2 expression levels to that of rats which were exposed to zinc only. As a result of these findings, zinc appears to have an incremental effect on renal TLR2 expression levels. Inversely, we observed that zinc has a decremental effect on renal TLR4 expression levels. Cigarette smoke has an opposite effect and this effect seems to be reversed by zinc.

In a study comparing the TLR 2 and TLR 4 expressions in nasal epithelial cells between the smoking and non-smoking groups, while the TLR2 level did not change, TLR4 was seen to decrease in the smoking group (MacRedmond et al., 2007). Similarly, in our study, TLR4 expression was lower in the group exposed to cigarete smoke, but we observed an increase in TLR2 level with the effect of smoke. In another study investigating apparently healthy individuals who smoke and stable chronic obstructive pulmonary disease (COPD) patients, TLR2 and TLR4 on CD14+ monocyte surfaces were seen to decrease (Nadigel et al., 2011). These differences from our study can have arisen from the difference in the selected tissues and the different methods used in the studies.

NFKB is a transcription factor which is activated in response to oxidative stress and which is responsible for the expression of many genes. In the literature, the effect of smoke on NFKB gene expressions is limited and shows differences. In our study, although not statistically significant, both cigarette smoke and zinc were found to have an incremental effect on the renal expression of NFKB1 and NFKB2 levels, while this effect was more prominent with the cigarette smoke. In previous studies, the increase in NFKB has been demonstrated in epithelial cells of the middle ear in bronchial biopsies of smokers (Li et al., 2011). The NFKB increase has been shown in the kidneys of diabetic rats in recent studies (Aras et al., 2010). Similarly, NFKB expression levels were seen to increase in our study. Since we could not find any study in the literature that investigates the levels of NFKB levels in cigarette smoke induced nephrotoxicity, we could not adeqauately discuss this possible relation.

Cytokines play important roles in the initiation and maintenance of inflammation. Tubular cells have the ability to synthesize cytokines. Cytokines and growth factors may be detected in the glomeruli of the patients in 
various nephropathies (Dundar et al., 2013). The effects of zinc supplementation on the levels of renal IL1 and IL10 expression in our study were similar to those on NFKB1 and 2 , which was an incremental effect.

In a study performed in cell cultures infected with RSV, smoke exposure was shown to lead to a decrease in IL1 and IL10 expression (Haeberle et al., 2004). These results are contrary to our results. In a recent study, similar to our findings, nicotine administration was reported to increase the IL1B level in the urogenital system, and this increase was reversed with resveratrol therapy (Toklu et al., 2010). However in the aforementioned research, IL1B was evaluated biochemically and the method used was different from that of our study.

The results of histopathological assessments are similar to those of previous studies (Kurus et al., 2009; Ozkurkcugil et al.,2011).Presence of a significant difference in the parameters between Group A and B, C and D indicated that smoke caused hemorrhage, congestion, inflammation, glomerular atrophy and tubular injury in the kidney; in other words, the model was correct. Absence of a significant difference between Group C and D indicated that dietary-supplemented zinc was not sufficiently effective for prevention of histopathological injury. The nicotine-induced anti-inflammatory effect against smoke-induced oxidative injury seems to be protective. Hence, the importance of developing drugs against nicotinic receptors has gained mention. However, sympathetic activation, increased cathecholamine release and thereby an increase in blood pressure and heart rate due to the effect of nicotine have been reported in many studies (Sung et al., 2001). Increased sympathetic activity has been reported to accelerate the progression of an existing renal disease (Amann et al., 2000; Sung et al., 2001). Thus, whether to benefit from the anti-inflammatory effect or to protect from the effect of sympathetic activation is still an issue of debate.

Prevention of smoke-induced toxicity is an important problem especially in patients with chronic renal failure and those who are candidates for transplantation. Studies with antioxidant agents that could prevent the toxic effects of smoke would be beneficial to prevent this morbidity besides fighting against smoking. Zinc, the deficiency of which develops very fast in all populations, is one of these antioxidants. Our study showed zinc may have a protective effect from smoke-induced nephrotoxicity. Additional studies are needed to clearly put forth both the direct and antioxidant effects of zinc in the tissue level.

\section{REFERENCES}

Amann, K., Rump, L.C., Simonaviciene, A., Oberhauser, V., Wessels, S., Orth, S.R., Gross, M.L., Koch, A., Bielenberg, G.W., Van Kats, J.P., Ehmke, H., Mall, G., Ritz, E., 2000. Effects of low dose sympathetic inhibition on glomerulosclerosis and albuminuria in subtotally nephrectomized rats. J. Am. Soc. Nephrol. 11, 1469-1478.

Aras, B., Tuğcu, V., Eren, G., Mutlu, B., Uhri, M., Özbek, E., Taşçı, A.İ., 2010. Protective effect of pyrrolidine dithiocarbamate on kidney tissue in streptozotocin-induced diabetic rats. Turkish J. Urology. 36, 167-175.

Chen, L., Sun, B.B., Wang, T., Wang, X., Li, J.Q., Wang, H.X., Zhang, S.F., Liu, D.S., Liu, L., Xu, D., Ou, X.M., Chen, Y.J., Yang, T., Zhou, H., Wen, F.Q., 2010. Cigarette smoke enhances $\{$ beta $\}$-defensin 2 expression in rat airways via nuclear factor- $\{$ kappa\} B activation. Eur Respir J. 36, 638-645.

Dundar, M., Kiraz, A., Balta, B., Emirogullari, E.F., Zararsiz, G., Yurci, A., Aslan, D., Baskol, M., 2013. The role of TNF- $\alpha$ and PAI-1 gene polymorphisms in familial Mediterranean fever. Mod. Rheumatol. 23, 140-145.

Gluba, A., Banach, M., Hannam, S., Mikhailidis, D.P., Sakowicz, A., Rysz, J., 2010. The role of Toll-like receptors in renal diseases. Nat. Rev. Nephrol. 6, 224-235.

Haeberle, H.A., Casola, A., Gatalica, Z., Petronella, S., Dieterich, H.J., Ernst, P.B., Brasier, A.R., Garofalo, R.P., 2004. IkappaB kinase is a critical regulator of chemokine expression and lung inflammation in respiratory syncytial virus infection. J. Virol. 78, $2232-2241$.

Khanna, A.K., Xu, J., Baquet, C., Mehra, M.R., 2009. Adverse effects of nicotine and immunosuppression on proximal tubular epithelial cell viability, tissue repair and oxidative stress gene expression. J. Heart Lung Transplant. 28, 612-620.

Kurus, M., Ugras, M., Esrefoglu, M., 2009. Smoke effect of resveratrol on tubular damage and interstitial fibrosis in kidneys of rats exposed to cigarette. Toxicol. Ind. Health. 25, 539-544.

Li, Q., Zhou, X.D., Kolosov, V.P., Perelman, J.M., 2011. Nicotine reduces TNF- $\alpha$ expression through a $\alpha 7$ nAChR/MyD88/NF- $x$ B pathway in HBE16 airway epithelial cells. Cell Physiol. Biochem. 27, 605-612.

Livak KJ, Schmittgen TD., 2001 Analysis of relative gene expression data using real-time quantitative PCR and the 2(-Delta Delta C(T)) Method. Methods. 4, 402-408

MacRedmond, R.E., Greene, C.M., Dorscheid, D.R., McElvaney, N.G., O’Neill, S.J., 2007. Epithelial expression of TLR4 is modulated in COPD and by steroids, salmeterol and cigarette smoke. Respir. Res. 8, 84 .

Murra, C., Pilz, S., Grammerc, T.B., Kleberc, M.E., Böhmd, B.O., Märzc, W., Fuchsa, D., 2012. Low serum zinc levels in patients undergoing coronary angiography correlate with immune activation and inflammation. J. Trace Elem. Med. Biol. 26, 26-30.

Nadigel, J., Prefontaine, D., Baglole, C.J., Maltais, F., Bourbeau, J., Eidelman, D., Hamid, Q., 2011. Cigarette smoke increases TLR4 and TLR9 expression and induces cytokine production from CD8+ T cells in chronic obstructive pulmonary Disease. Respir. Res. $12,149$.

Orth, S.R., 2002. Smoking and the kidney. J. Am. Soc. Nephrol. 13, 1663-1672.

Ozbek, E., 2012. Induction of oxidative stress in kidney. hindawi publishing corporation international. Int. J. Nephrol. doi: 10.1155/2012/465897.

Ozkurkcugil, C., Yardimoglu, Y.M., Ozkan, L., Kokturk, S., Isken, T., 2011. Protective effects of pentoxifylline on cigarette smoking-induced renal tissue damage in rats. Toxicol. Ind. Health. 27, 335-340.

Pedregosa, J.F., Haidar, A.A., Hirata, A.E., Franco, M., Gomes, G.N., Bueno, V., 2011. TLR2 and TLR4 expression after kidney ischemia and reperfusion injury in mice treated with TY720. Int. Immunopharmacol. 11, 1311-1318.

Ryua, M.S., Bobbi, L.H., Changa, S.M., Shankarb, M.N., Cousinsa, R.J., 2011. Genomic analysis, cytokine expression, and microRNA profiling reveal biomarkers of human dietary zinc depletion and homeostasis PNAS. 108, 20970-20975.

Sung, R.S., Althoen, M., Howell, T.A., Ojo, A.O., Merion, R.M., 2001. Excess risk of renal allograft loss associated with cigarette smoking. Transplantation. 71, 1752-1757.

Toklu, H., Şehirli, O., Şahin, H., Çetinel, S., Yeğen, B., Şener, G., 2010. Resveratrol supplementation protects against chronic nicotine-induced oxidative damage and organ dysfunction in the rat urogenital system. Marmara Pharmaceutical Journal. 14, 29-40. 